\title{
Crown-Size Profile Pattern in Trisomy G
}

\author{
M. MICHAEL COHEN, STANLEY M. GARN, and MICHAEL A. GECIAUSKAS \\ Department of Oral Pathology, Tufts University, Boston, Massachusetts and Center for \\ Human Growth and Development, University of Michigan, Ann Arbor, Michigan
}

In third molar agenesis and in more extensive tooth number reduction, crown size of the remaining teeth is reduced and a new crown-size profile pattern emerges, along with a gradient of reduction diminishing along a mesial to distal axis. Crown-size reduction also characterizes Down's syndrome (mongolism), ie, trisomy G (M. M. CoHEN and R. A. Winer, $J$ Dent Res 44:197-208, 1965; and M. M. CoHeN and M. A. Geciauskas, $J$ Ment $D i s$, in press, 1969). The question is whether the pattern of crown-size reduction in trisomy $G$ resembles the pattern in simple or multiple agenesis.

Mesiodistal crown-size measurements were taken of 21 males and 29 females with Down's syndrome. The raw scores were converted into $Z$-score or $T$-score values, in terms of a single reference population (S. M. GARN, A. B. LEwIS, and A. J. WálengA, Arch Oral Biol 13:841-844, 1968). The crown-size profile pattern was plotted (S. M. GARN, A. B. Lewis, and A. J. WALENGA, J Dent Res 47:1190, 1968; and S. M. Garn, A. B. LewIS, and A. J. Walenga, $A r c h$ Oral Biol 13:1235-1242, 1968) using a Calcomp Digital Incremental Plotter* and a special computer program. The pattern was compared to that in hypodontia, using the statistic $r_{T}$ to measure pattern profile similarity (S. M. GARN, A. B. LeWIS, and A. J. WALENGA, $J$ Dent Res 47:1190, 1968; and Amer Anthrop 71:79-84, 1969).

As shown in the Illustration, traced from the Calcomp plot, crown-size reduction is extensive in both sexes in Down's syndrome, and the crown-size pattern differs from that of the ref-

Statistical program was supported by USPHS Research Grant HD-02272 from the National Institute of Child Health and Human Development, Bethesda, Md.

William R. D'Angelo of the Growth Center Computer Group and Anne Brighton assisted in the data analysis.

Additional information available on request to authors.

Received for publication June 24, 1969.

* California Computer Products Inc., Anaheim, Calif 92803 . erence population. Although the crown-size pattern is similar in both males and females with Down's syndrome, as shown by the $r_{T}$ value of 0.95 , it differs from that in multiple agenesis (S. M. GARN and A. B. LewIS, Angle Orthodont, in press, 1970 ) as shown by negative values of $r_{T},-0.10$ in males and -0.19 in females. In particular, the mesial to distal gradient of reduction is replaced by a more complex and distinctly different pattern of crownsize reduction in trisomy $G$.

The results indicate that an extra autosome affects both sexes similarly in contrast to the action of the apparently X-linked gene in simple hypodontia. Further, the distinctly different pattern of crown-size reduction in Down's syndrome suggests a specificity of patterned response, such that other autosomal reduplications and translocations should show specific crownsize profile-pattern alterations.

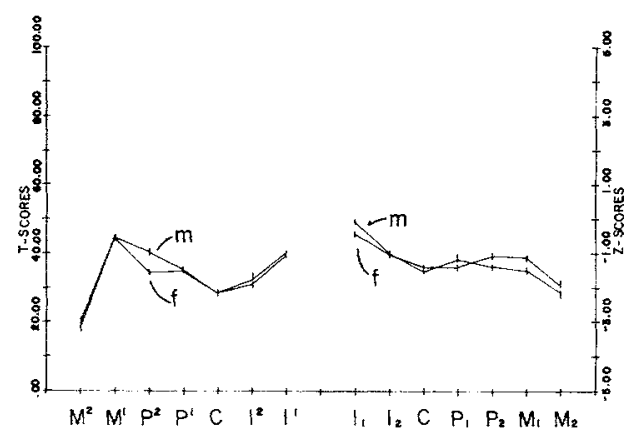

Crown-size profile patterns of the mesiodistal diameters of 50 individuals with Down's syndrome showing size reduction, deviation from the normal pattern, and close similarity of the patterned reduction in both males and females with Down's syndrome $\left(r_{T}=0.95\right)$. 